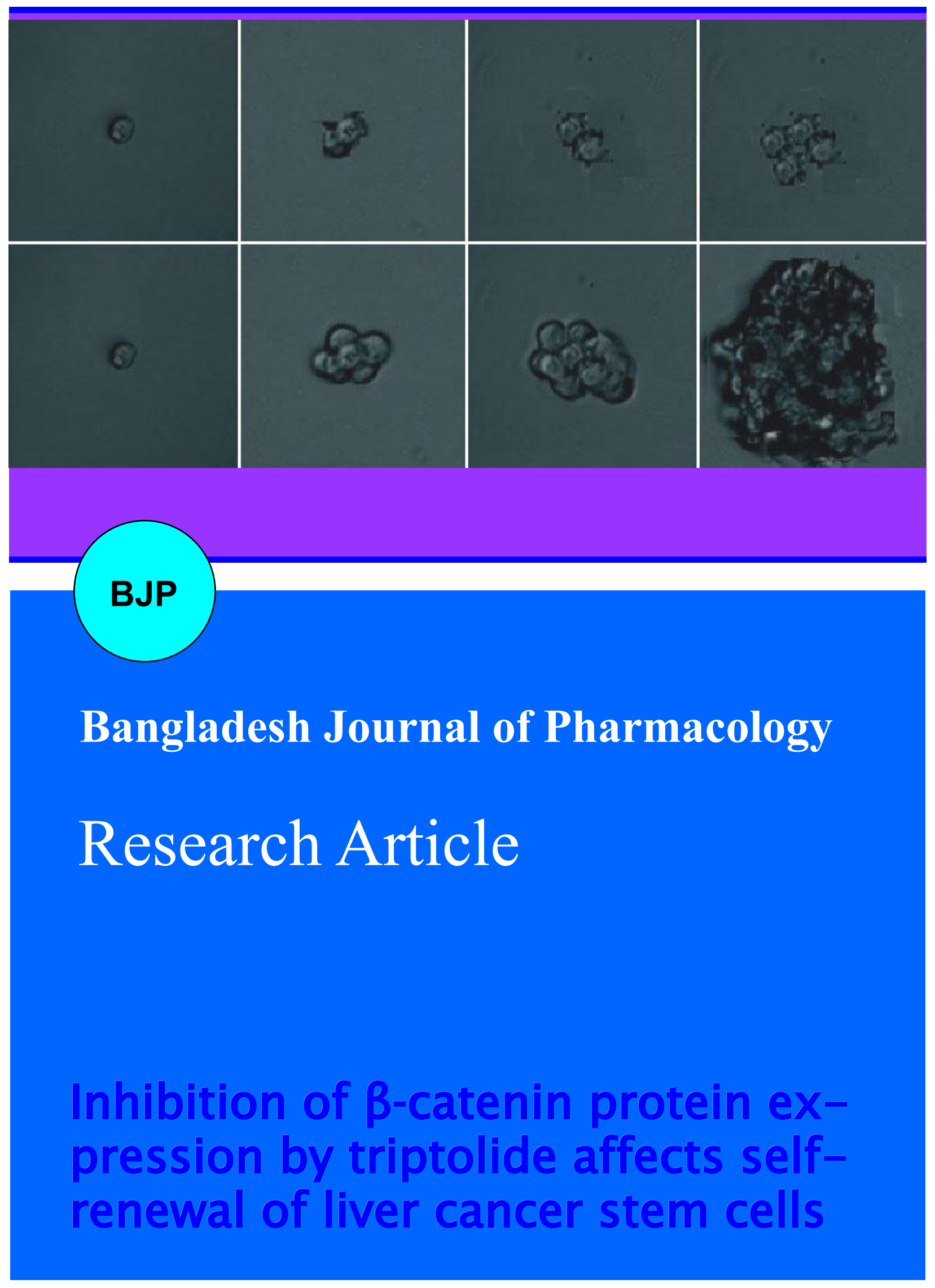


Abstracted/indexed in Academic Search Complete, Agroforestry Abstracts, Asia Journals Online, Bangladesh Journals Online, Biological Abstracts, BIOSIS Previews, CAB Abstracts, Current Abstracts, Directory of Open Access Journals, EMBASE/Excerpta Medica, Google Scholar, HINARI (WHO), International Pharmaceutical Abstracts, Open J-gate, Science Citation Index Expanded, SCOPUS and Social Sciences Citation Index;

ISSN: $1991-0088$

\title{
Inhibition of $\beta$-catenin protein expression by triptolide affects self-renewal of liver cancer stem cells
}

\author{
Jian-Bo Zhou, Gang Peng, Yu-Cheng Jia, Jun Li, Jia Wang, Shu Nie and Qiu-Ying Zhang \\ Department of General Surgery, Suizhou Hospital, Hubei University of Medicine, Suizhou 441 300, China.
}

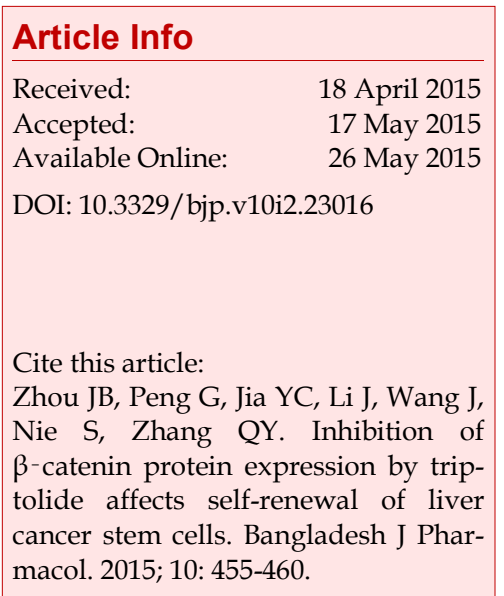

\begin{abstract}
The present study demonstrates the effects of triptolide, one of the constituents from Tripterygium wilfordii, on the self-renewal capacity of human hepatocellular carcinoma. The investigation revealed that triptolide markedly prevented the proliferation of liver cancer stem cells (LCSCs). For the LCSCs the minimum inhibitory concentration of triptolide was $0.6 \mu \mathrm{M}$. There was a significant and obvious decrease in the capacity of LCSCs to form self-sphere. Furthermore, triptolide reduced the sphere-forming capacity of LCSCs along with inhibition of $\beta$-catenin expression. However, the exposure of triptolidetreated cells to lithium chloride, an activator the Wnt/ $\beta$-catenin signaling pathway, reversed the triptolide-induced inhibition of $\beta$-catenin expression and inhibited the self-renewal capacity. Therefore, triptolide effectively eradicates LCSCs through the inhibition of $\beta$-catenin protein and may act as a novel agent for the treatment of hepatocellular carcinoma.
\end{abstract}

\section{Introduction}

Hepatocellular carcinoma, the fifth most common malignancy in males and seventh in females, is the third leading cause of cancer-related mortality worldwide (Ma et al., 2008; Tomuleasa et al., 2010). In 2008 the number of new liver cancer cases and cancer mortalities reported globally were 748,300 and 695,900 respectively (Jemal et al., 2011). Despite advances in the diagnostic techniques and treatment strategies for hepatocellular carcinoma, the prognosis remains poor for patients with hepatocellular carcinoma (Shin and Chung, 2013). The major limitation associated with hepatocellular carcinoma is the appearance of late stages clinical symptoms and a high rate of metastases (Trevisani et al., 2008; Yang et al., 2007). Thus, the discovery of novel molecules with the roles in inhibition of hepatocellular carcinoma is highly desired.

A group of cells possessing stem cell properties and ability of propagating and sustaining tumors are known as cancer stem cells (CSCs) (Mackillop et al., 1983; Gupta et al., 2009). CSCs provide resistance to chemo- therapy and radiotherapy and are also responsible for the progression of tumors to distant areas (Chiba et al., 2006). The markers of human liver cancer stem cells (LCSCs) include cluster of differentiation (CD)133, CD90, CD44, epithelial cell adhesion molecule, OV6 and CD13 (Yang et al., 2008; Ma et al., 2007; Zhu et al., 2010; Kimura et al., 2010; Haraguchi et al., 2010). Cells lacking such markers exhibit LCSC properties; therefore, individual markers may not be sufficient to represent all of the characteristics of CSCs (Salnikov et al., 2009).

Tripterygium wilfordii Hook $\mathrm{f}$ has a long history of use in traditional Chinese medicine and its phytochemical investigation lead to the isolation of triptolide. Latter on it was found that triptolide exhibits immunosuppressor, anti-cancer, and contraceptive activities (Zhen et al., 1995; Tengchaisri et al., 1998; Hachida et al., 1999). It was also reported to induce apoptosis through cytochrome c release and by reducing the anti-apoptotic proteins expression (Carter et al., 2006). This leads to the appearance of characteristic morphological and biochemical changes (Cohen, 1993; White, 1996). Our 
study revealed that triptolide markedy inhibits the selfrenewal capacity of $\mathrm{CD} 133+$ sphere-forming cells (SFCs) of the MHCC97 cell line, namely LCSCs, through the reduction in $\beta$-catenin expression.

\section{Materials and Methods}

\section{Cell lines and culture}

HepG2 hepatocellular carcinoma cell line was purchased from American Type Culture Collection (Manassas, USA). The cells were maintained in Dulbecco's modified Eagle's medium (DMEM) supplemented with $10 \%$ fetal bovine serum (HyClone, Logan, USA), supplemented with antibiotics (Invitrogen Life Technologies, Carlsbad, CA, USA) and were incubated in an atmosphere of $5 \% \mathrm{CO}_{2}$ at $37^{\circ} \mathrm{C}$.

\section{Drug and reagents}

Triptolide was purchased from (Calbiochem, San Diego, CA, USA) and its stock solution was prepared in DMSO. MTT and lithium chloride were obtained from Santa Cruz Biotechnology (Santa Cruz, CA, USA) whereas trypsin and DMSO were supplied by SigmaAldrich (St. Louis, MO, USA). The antibodies like mouse anti-human $\beta$-catenin, cyclin D1, and horseradish peroxidase-conjugated rabbit anti-mouse secondary antibody was obtained from Cell Signaling Technology (San Diego, CA, USA).

\section{MTT assay}

We used MTT [3-(4,5-dimethylthiazol-2-yl)-2,5diphenyltetrazolium bromide, a tetrazole] reduction conversion assay to analyze the cell viability. Briefly, HepG2 cells grown at a density of $2.5 \times 10^{5}$ in 96-well plates were treated with triptolide for 48 hours. The cells were then incubated with $100 \mu \mathrm{L}$ of MTT $(5 \mathrm{mg} /$ $\mathrm{mL}$ ) for 2 hours. Dimethyl sulfoxide was added to dissolve the formazan crystals fromed during conversion of MTT by mitochondrial enzymatic activity. The microplate reader (Molecular Devices, CA, USA) was used to measure the absorbance at $570 \mathrm{~nm}$. The absorbance of MTT-treated cells relative to that of untreated cells was taken as the measure of cell survival.

\section{Western blot analysis}

The triptolide treated cells were lysed, and using dyebinding method (Bio-Rad) protein concentration was determined. The proteins were resolved on 15\% SDSPAGE and transferred to nitrocellulose membranes. Digitonin-based subcellular fractionation technique was used for cytosolic and mitochondrial fractions. Onto DS -PAGE equal volumes of cytosolic and mitochondrial fractions were resolved and transferred to nitrocellulose membranes. The membranes after incubation with primary antibody ( $\beta$-catenin, cyclin D1 or $\beta$-actin) were washed, and then incubated with horseradish peroxidase anti-mouse or horseradish peroxidase antirabbit antibodies. Enhanced chemilumi-nescence system was used for visualization of immuno-reactive bands. The role of lithium chloride in the triptolideinduced inhibition of $\beta$-catenin or cyclin D1 protein expression was investigated by incubation of cells in medium containing casticin and lithium chloride .

\section{Cell sorting and sphere culture}

We used magnetic activated cell sorting (MACS) separation columns (Miltenyi Biotec, Bergisch Gladbach, Germany) to examine cell surface phenotype, CD133+ according to the manufac-turer's instructions. The cells $\left(2.5 \times 10^{6}\right)$ after trypsinization and phosphatebuffered saline (PBS) washing were treated with FcR blocking reagent $(100 \mu \mathrm{L}$; anti-CD133 antibody) and 100 $\mu \mathrm{L} \quad$ CD133 -conjugated MicroBeads (AC133 Cell Isolation Kit, Miltenyi Biotec). The cells were then incubated for $30 \mathrm{~min}$ on ice and washed again. The magnetic activated cell sorting (MACS) separation columns (Miltenyi Biotec, Bergisch Gladbach, Germany) were used to isolate CD133 -positive and -negative fractions. The CD133+ and parental cells were suspended in serum-free medium, supplemented with $20 \mathrm{ng} / \mathrm{mL}$ human recombinant epidermal growth factor (EGFR), $20 \mathrm{ng} / \mathrm{mL}$ human recombinant basic fibroblast growth factor, 2\% B27 supplement without vitamin A, $0.4 \% \mathrm{BSA}, 4 \mathrm{ng} / \mathrm{mL}$ insulin and antibiotics. The cells were then seeded into ultra-low attachment six-well plates (Corning, Inc., Corning, NY, USA) and passaged every six days after the spheroid diameter reached 50 $\mu \mathrm{m}$. The microscope (IX71, Olympus, Tokyo, Japan) was used to count colonies in 10 different views. The volume of the spheroids $\left(\mu \mathrm{m}^{3}\right)$ was estimated using the following formula: $V=(4 \square 3) \Pi^{3}$, where $R$ denotes radius. The experiments were repeated three times in duplicate.

\section{Flow cytometry (FCM)}

The parental, sorted CD133+ and CD133- cells at a density of $2.5 \times 10^{6}$ in PBS were incubated with mouse anti-human CD133-R-phyco-erythrin (PE) and mouse IgG2b isotype control-PE monoclonal antibodies. After 45 min incubation in dark FCM was used to measure the fluorescence.

\section{Spheroid passage and sphere formation assay}

The CD133+ cells after dissociation with trypsin-EDTA were mechanically disrupted followed by centrifugation to remove the enzyme. The cells were suspended in culture medium and allowed to reform spheres. Every six days the tumorspheres were passaged until the diameter reached $50 \mu \mathrm{m}$. The wells bearing single cells examined every day for 10 days using inverted microscope (IX71, Olympus).

The single-cell suspension $\left(2 \times 10^{5}\right.$ cells $\left./ \mathrm{mL}\right)$ was sus- 
pended onto six-well plates in primary experiment where as in secondary experiment $2.5 \times 10^{4}$ cells $/ \mathrm{mL}$ were suspended. The medium for primary experiment contained different concentrations of triptolide. Some of the plates also contained culture medium containing triptolide-lithium chloride for 24 hours to investigate relationship of $\mathrm{Wnt} / \beta$-catenin pathway and formation of sub-tumorspheres.

\section{Statistical analysis}

All the results are the means of \pm SD. SPSS software, version 15.0 (SPSS, Inc., Chicago, IL, USA) was used for the analysis of the data and one-way analysis of variance was performed. The differences were considered statistically significant at $\mathrm{p}<0.05$.

\section{Results}

Inhibition of LCSC proliferation and self-renewal by triptolide
We investigated the secondary tumorspheres formed by the single cells within 10 days of culture. The undifferentiated CD133+ HepG2 hepatocellular carcinoma cells formed new spheroids after 10 days of culture (Figure 1).

MTT assay was used to analyze the effect of various triptolide concentrations on the viability of parental and CD133+ HepG2 cells. Triptolide exhibited a concentration dependent effect on the inhibition of CD133+ HepG2 cell viability (Figure 2A). For parental cells and the CD133+ HepG2 the $\mathrm{IC}_{50}$ value of triptolide was observed to be $0.6 \mu \mathrm{M} / \mathrm{mL}$.

Exposure of primary tumorspheres to a range of triptolide concentrations $(0.1,0.2,0.4,0.6,0.8$ and 1.0 $\mu \mathrm{M})$ for 24 hours was followed by incubation in triptolide free medium. The results showed a marked decrease in the LCSC primary as well secondary tumorspheres (Figure 2B). Triptolide treatment also exhibited inhibitory effect and significantly reduced self -renewal capacity of LCSCs.

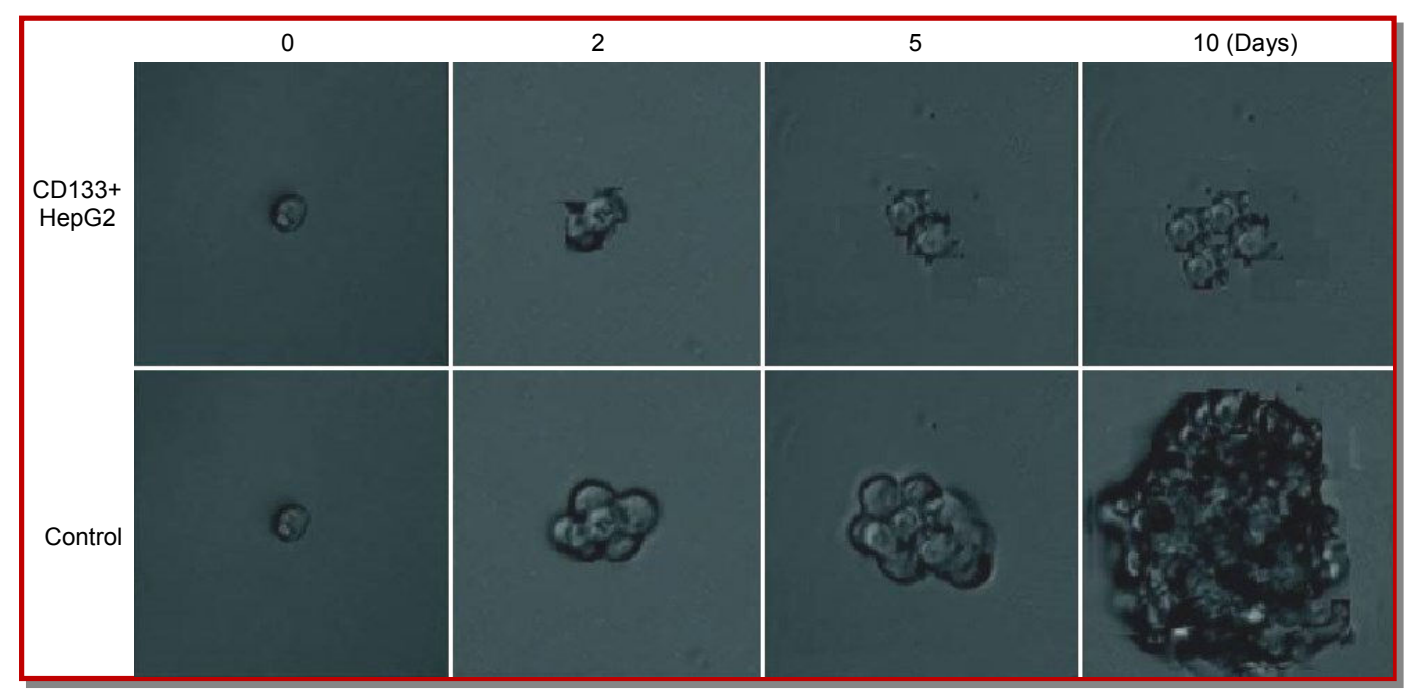

Figure 1: The sphere formation of single cells in six-well plates was detected on the day 2, 5 and 10 (magnification, x400)

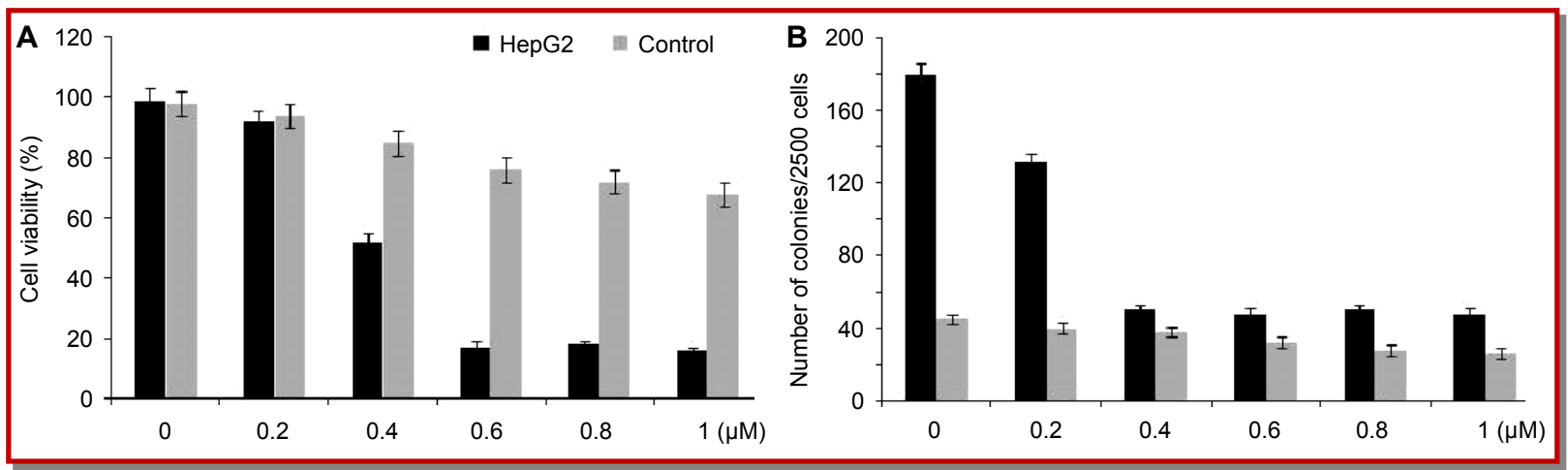

Figure 2: Triptolide preferentially inhibits proliferation and self-renewal of CD133+ HepG2 LCSCs. Casticin preferentially inhibited proliferation of CD133+ HepG2 (A) HepG were incubated with indicated concentrations of triptolide or DMSO for 10 days; (B) Data are expressed as the mean \pm standard deviation $(n=3)$ 


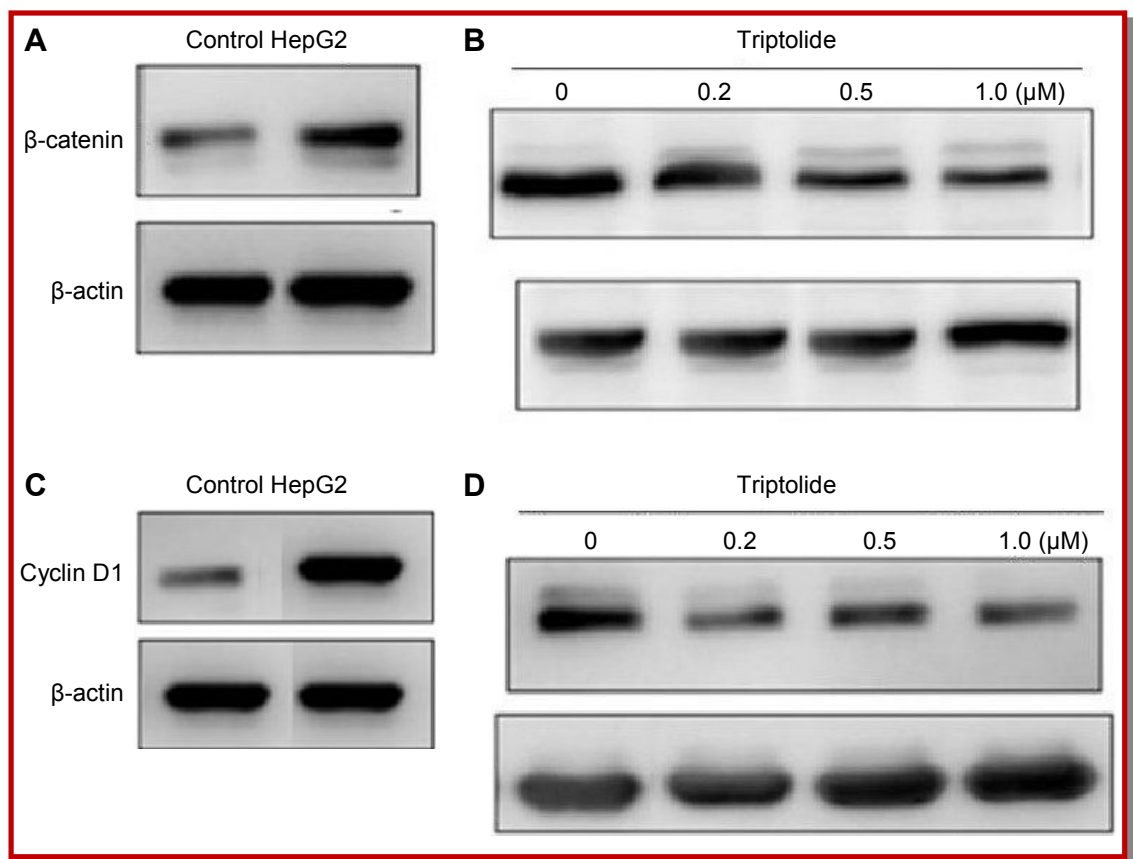

Figure 3: Triptolide inhibits $\beta$-catenin and cyclin D1 protein expression in LCSCs. (A) $\beta$-catenin is highly expressed in CD133+ HepG2 compared with untreated control; (B) Triptolide reduced the expression of $\beta$-catenin in CD133+ HepG2 cells; (C) Cyclin D1 is highly expressed in CD133+ HepG2 compared with corresponding untreated control; (D) Triptolide down-regulated the expression of cyclin D1 in CD133+ HepG2 cells

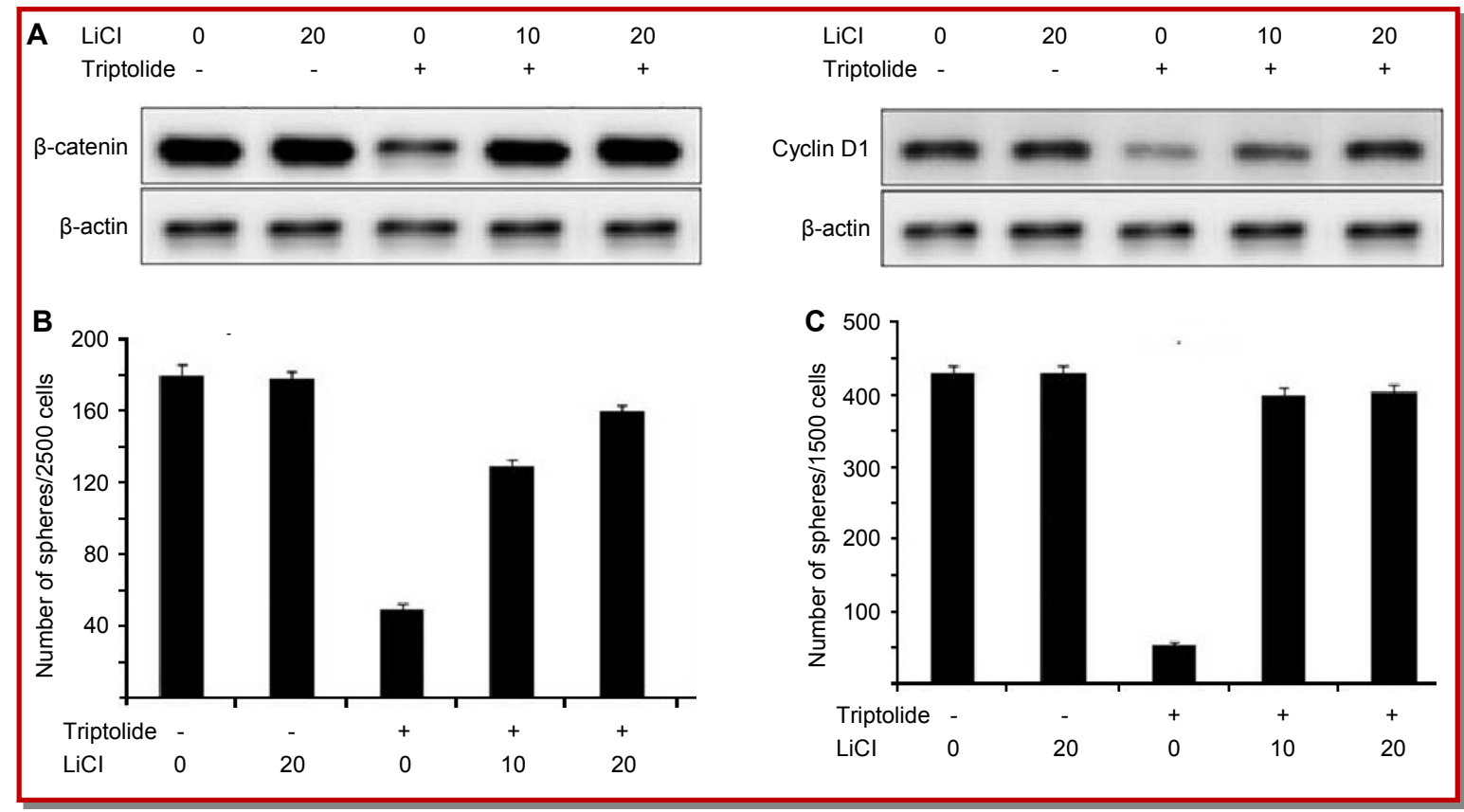

Figure 4: Lithium chloride treatment antagonized the inhibitory effects of triptolide on the self-renewal of LCSCs. Effects of triptolide and/or lithium chloride on expression of $\beta$-catenin (A, left) and cyclin D1 (A, right). Effects of triptolide and/or lithium chloride on the number of tumorspheres formed from CD133+ HepG2 cells (B and C) 
Inhibits of self-renewal in LCSCs by triptolide proceeds through modulation of $\beta$-catenin expression

Western blot analysis showed a markedly higher expression of $\beta$-catenin and cyclin D1 proteins in LCSCs compared to that in parental cells. However, a significant decrease in the expression of $\beta$-catenin and cyclin D1 in the LCSCs was caused on treatment with $0.3 \mu \mathrm{M}$ of triptolide (Figure 3).

When triptolide-treated LCSCs were exposed to lithium chloride which acts as an agonist for the activation of $W n t / \beta$-catenin pathway, the expression of $\beta$-catenin and cyclin D1 proteins was increased. The self-renewal ability of triptolide treated LCSCs was also enhanced on exposure to lithium chloride (Figure 4). Since Wnt $/ \beta$ -catenin signaling pathway acts as a significant regulator of stem cell self-renewal, the inhibition of selfrenewal in LCSCs by triptolide involves modulation of $\beta$-catenin expression.

\section{Discussion}

A number of studies have revealed that selective targeting of cancer stem cells is of significant utility in the cancer therapeutics (Naujokat and Steinhart, 2012). These studies have shown that among other CSC therapeutic targets Wnt/ $\beta$-catenin is also of marked significance (Wang et al., 2010; Liu et al., 2009). The present study was performed to demonstrate the effect of triptolide on CSCs which are found frequently in solid tumors. LCSCs were isolated based on the presence of cell surface marker, CD133+ by using MACS. These cells where cultured in the stem cellconditioned medium and allowed to form threedimensional spheres. There was suppression of HepG2 cell viability on triptolide treatment compared with the parental cells. These findings were in consistence with those reported earlier for casticin elsewhere (Feng et al., 2012). Triptolide treated HepG2 cells showed reduction in the sphere-forming capacity and inhibited proliferation and self-renewal of LCSCs.

The self-renewal and differentiation of LCSCs is maintained by $\mathrm{Wnt} / \beta$-catenin signaling pathway. It is also responsible for the development of resistance by LCSCs to various chemotherapeutic strategies. It is reported that PKF118-310 inhibits Wnt/ $\beta$-catenin signaling in breast tumor-initiating cells thereby inhibiting their self-renewal (Li et al., 2012). CDH11 induces inhibition of actin stress fiber formation which in turn suppresses migration and invasion of tumor cells through modulation of Wnt/ $\beta$-catenin signaling (Li et al., 2012). Our results revealed that the expression of $\beta$-catenin and cyclin D1 was higher in the LCSCs which were inhibited when the cells were treated with triptolide. Furthermore, lithium chloride treatment caused inhibition of the self-renewal capacity by LCSCs.
Our findings indicate that triptolide regulates selfrenewal of LCSCs by down-regulating the expression of $\beta$-catenin.

\section{Conclusion}

The present study demonstrates that triptolide inhibits the self-renewal capacity of LCSCs through inhibition of Wnt/ $\beta$-catenin signaling path-way. Therefore, triptolide can have a therapeutic role in the treatment of hepatocellular carcinoma.

\section{References}

Carter BZ, Mak DH, Schober WD, McQueen T, Harris D, Estrov Z, Evans RL, Andreeff M. Triptolide induces caspasedependent cell death mediated via the mitochondrial pathway in leukemic cells. Blood 2006; 108: 630-37.

Chiba T, Kita K, Zheng YW, Yokosuka O, Saisho H, Iwama A, Nakauchi $\mathrm{H}$, Taniguchi $\mathrm{H}$. Side population purified from hepatocellular carcinoma cells harbors cancer stem cell-like properties. Hepatology 2006; 44: 240-51.

Cohen JJ. Apoptosis. Immunol Today. 1993; 14: 126-30.

Feng X, Zhou Q, Liu C, Tao ML. Drug screening study using glioma stem-like cells. Mol Med Rep. 2012; 6: 1117-20.

Gupta PB, Chaffer CL, Weinberg RA. Cancer stem cells: Mirage or reality? Nat Med. 2009; 15: 1010-12.

Haraguchi N, Ishii H, Mimori K, Tanaka F, Ohkuma M, Kim HM, Akita H, Takiuchi D, Hatano H, Nagano H, Barnard GF, Doki Y, Mori M. CD13 is a therapeutic target in human liver cancer stem cells. J Clin Invest. 2010; 120: 3326-39.

Hachida M, Lu H, Zhang X, Saito S, Furutani Y, Matsuoka R, Hoshi $\mathrm{H}$, Koyanagi $\mathrm{H}$. Inhibitory effect of triptolide on platelet derived growth factor-A and coronary arteriosclerosis after heart transplantation. Transplant Proc. 1999; 7: 2719-23.

Jemal A, Bray F, Center MM, Ferlay J, Ward E, Forman D. Global cancer statistics. CA Cancer J Clin. 2011; 61: 69-90.

Kimura O, Takahashi T, Ishii N, Inoue Y, Ueno Y, Kogure T, Fukushima K, Shiina M, Yamagiwa Y, Kondo Y, Inoue J, Kakazu E, Iwasaki T, Kawagishi N, Shimosegawa T, Sugamura K. Characterization of the epithelial cell adhesion molecule (EpCAM)+ cell population in hepatocellular carcinoma cell lines. Cancer Sci. 2010; 101: 2145-55.

Li L, Ying J, Li H, et al. The human cadherin 11 is a proapoptotic tumor suppressor modulating cell stemness through Wnt/beta-catenin signaling and silenced in common carcinomas. Oncogene 2012; 31: 3901-12.

Liu J, Kopecková $\mathrm{P}$, Bühler $\mathrm{P}$, et al. Biorecognition and subcellular trafficking of HPMA copolymer-anti-PSMA antibody conjugates by prostate cancer cells. Mol Pharm. 2009; 6: 959-70.

Mackillop WJ, Ciampi A, Till JE, Buick RN. A stem cell model of human tumor growth: Implications for tumor cell 
clonogenic assays. J Natl Cancer Inst. 1983; 70: 9-16.

Ma S, Chan KW, Hu L, et al. Identification and characterization of tumorigenic liver cancer stem/progenitor cells. Gastroenterology 2007; 132: 2542-56.

Ma S, Chan KW, Guan XY. In search of liver cancer stem cells. Stem Cell Rev. 2008; 4: 179-92.

Naujokat C, Steinhart R. Salinomycin as a drug for targeting human cancer stem cells. J Biomed Biotechnol. 2012: 950658.

Salnikov AV, Kusumawidjaja G, Rausch V, et al. Cancer stem cell marker expression in hepatocellular carcinoma and liver metastases is not sufficient as single prognostic parameter. Cancer Lett. 2009; 275: 185-93.

Shin JW, Chung YH. Molecular targeted therapy for hepatocellular carcinoma: Current and future. World J Gastroenterol. 2013; 19: 6144-55.

Tengchaisri T, Chawengkirttikul R, Rachaphaew N, Reutrakul V, Sangsuwan R, Sirisinha S. Anti-tumor activity of triptolide against cholangiocarcinoma growth in vitro and in hamsters. Cancer Lett. 1998; 133: 169-75.

Tomuleasa C, Soritau O, Rus-Ciuca D, et al. Isolation and characterization of hepatic cancer cells with stem-like properties from hepatocellular carcinoma. J Gastrointestin
Liver Dis. 2010; 19: 61-67.

Trevisani F, Cantarini MC, Wands JR, Bernardi M. Recent advances in the natural history of hepatocellular carcinoma. Carcinogenesis 2008; 29: 1299-305.

Wang Z, Li Y, Ahmad A, et al. Targeting miRNAs involved in cancer stem cell and EMT regulation: An emerging concept in overcoming drug resistance. Drug Resist Updat. 2010; 13: 109-18.

White E. Life, death, and the pursuit of apoptosis. Genes Dev. 1996; 10: 1-15.

Yang Y, Nagano H, Ota H, et al. Patterns and clinicopathologic features of extrahepatic recurrence of hepatocellular carcinoma after curative resection. Surgery 2007; 141: 196-202.

Yang ZF, Ho DW, Ng MN, et al. Significance of CD90+ cancer stem cells in human liver cancer. Cancer Cell. 2008; 13: 15366.

Zhen QS, Ye X, Wei ZJ. Recent progress in research on Tripterygium: A male antifertility plant. Contraception 1995; 51: 121-29.

Zhu Z, Hao X, Yan M, et al. Cancer stem $\square$ /progenitor cells are highly enriched in CD133+CD44+ population in hepatocellular carcinoma. Int J Cancer. 2010; 126: 2067-78. 